Entrevistas

\title{
Reflexiones sobre música actual. Entrevista a Luis Grorelik
}

Loudet, Pablo

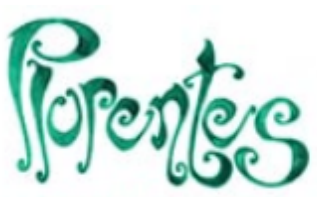

Artes y Letras

\section{Pablo Loudet \\ ploudet@gmail.com \\ Bachillerato de Bellas Artes, Universidad Nacional de \\ La Plata, Argentina}

Plurentes. Artes y Letras

Universidad Nacional de La Plata, Argentina

ISSN: $1853-6212$

Periodicidad: Anual

núm. 12, e031, 2021

revistaplurentesunlp@gmail.com

Recepción: 01 Septiembre 2021

Aprobación: 06 Septiembre 2021

Publicación: 29 Octubre 2021

URL: http://portal.amelica.org/ameli/

jatsRepo/186/1862378009/index.html

DOI: https://doi.org/10.24215/18536212e031

\section{(1) (3)}

Esta obra está bajo una Licencia Creative Commons AtribuciónNoComercial-CompartirIgual 4.0 Internacional.

Luis Gorelik comenzó sus estudios en el Bachillerato de Bellas Artes de la UNLP, colegio del que egresó en 1980. Desde aquel momento inició una importante y extensa carrera en el mundo de la música, destacándose como director de orquesta.

Se formó con Pedro I. Calderón en Argentina y con Mendi Rodán en Israel, donde se graduó con distinción en la Academia de Música Rubin de Jerusalem.

A temprana edad comenzó su actividad profesional como Director Titular de la Orquesta Filarmónica de Mendoza en 1985. Tres años después se radicó en Israel, donde continuó sus estudios de post grado y fue invitado a dirigir las principales orquestas de ese país ${ }^{1}$. Ganó por concurso el cargo de Director Asistente de la Orquesta Sinfónica de Haifa que dirigió entre 1991 y1993 y luego el de Director Titular de la Orquesta de Cámara de Ashdod entre 1993 y 1999.

Vuelto a Latinoamérica, en el año 2000 fue nombrado Director Titular de la Orquesta Sinfónica Universidad de Concepción de Chile, cargo que ocupó durante siete temporadas. Junto a esa orquesta, en 2004 obtuvo de manos del Presidente de Chile, Ricardo Lagos, el Premio a la Música y luego en 2005, el Premio de Arte y Cultura, Medalla Claudio Arrau.

En 2007 obtuvo por concurso el cargo de Director Titular de la Orquesta Sinfónica de Salta, frente a la cual realizó tres exitosas temporadas y grabó para Sony Classical el CD 200 años de Música Argentina. En 
2009 recibió el Premio Konex, como Director de Orquesta Destacado de la Década. Entre 2016 y 2018, fue director artístico de la Orquesta Nacional de Música Argentina “Juan de Dios Filiberto”.

El Maestro Gorelik es regularmente invitado a dirigir en las temporadas sinfónicas y coreográficas del Teatro Colón de Buenos Aires y la Orquesta Sinfónica Nacional de Argentina. Como director de ópera y ballet ha participado, además, en las temporadas de diversos teatros ${ }^{2}$ y en producciones junto al Bejart Ballet Lausanne. También se destacan varias de sus presentaciones ${ }^{3}$ en cuyos teatros ha tenido a su cargo la concertación de distintas óperas. ${ }^{4}$

Actualmente es el director artístico de la Orquesta Sinfónica de Entre Ríos (cargo que ocupa desde 2010), también es Profesor Titular de la Cátedra de Dirección Orquestal en la UNA (Universidad Nacional de las Artes) y desde 2011 conduce semanalmente el programa radial Tarde transfigurada, que se emite por Radio Nacional Clásica 96.7.

Con permanente presencia y actividad en Internet, a través de su página web http://www.luisgorelik.com, Instagram@gorelikluis y Facebook, el Maestro Gorelik ha sembrado en la web varias ideas que forman parte de su pensamiento musical. Esta entrevista pretende compartir y profundizar algunas de ellas.

PL: Resultan interesantes una serie de ideas que expresás en diversas publicaciones; particularmente, en una entrevista hablás de la necesidad de deconstruir el concepto de música actual. ¿Qué implicaría este concepto de deconstrucción?

LG: Así es. Soy de la idea de que la clasificación de "Música contemporánea" a todo lo producido a partir de la Escuela de Viena y sus derivados es incompleta y estrecha. Coincido con Arnold Schoenberg en que la modernidad de la música deriva de su idea y no de su estilo y ello no siempre tiene que ver con una cuestión cronológica. Es muchísimo más moderna la Gran Fuga Op. 133 de Beethoven que una obra de Philip Glass, por ejemplo.

PL: ¿Cómo definirías la música actual a partir de esa idea?

LG: Hago una diferencia entre "Música actual" y "Música moderna", es decir, actualidad tiene que ver con la temporalidad de su escritura, pero modernidad tiene que ver, al menos para mí, con lo profundo de su idea en cuanto funciona como apertura a nuevos caminos estéticos.

PL: Teniendo en cuenta esa definición, ¿considerás que podría hablarse en nuestro siglo XXI de la existencia de una vanguardia musical?

LG: No lo sé, realmente. Me gusta pensar el término "vanguardia" como su real significado: separado del resto, que no tiene nadie adelante. En música es necesaria una perspectiva temporal para apreciar quienes son vanguardia y quienes no. Muchas veces movimientos conceptuales como el futurismo, que a pesar de no tener una incidencia significativa en el plano de la representación instalaron una paleta de recursos que fue tomada varios años después, terminan siendo las verdaderas vanguardias. Eso, en todo caso, es difícil de apreciar sin una perspectiva de tiempo.

PL: Atendiendo al panorama actual en nuestro país y sin dejar de lado la perspectiva histórica ¿̨pensás que existe la "argentinidad" en la música?

LG: Lo digo siempre: no existe un coeficiente de argentinidad musical. ¿Quién es más argentino: Roberto Rimoldi Fraga o Mauricio Kager? El primero, golpeándose el pecho y gritando ¡Argentino hasta la muerte!; el segundo, riéndose de los gestos estereotipados del imaginario musical vernáculo a través de obras maestras como "Tango Alemán”. Y todo lo que entra en ese amplio arco simbólico... Creo que lo único verdaderamente argentino y que nos define como tales es la diversidad.

PL: En una de tus publicaciones, hablás de la interpretación musical como forma de traducción, ¿en qué sentido interpretar es traducir? 
LG: La traducción es una relectura. Cuando un intérprete acomete la construcción de una versión lo que está haciendo es traducir el texto original (partitura, en este caso) a través de su mirada y su bagaje. Me gusta repetir la cita de Borges expresando que "La noción de texto definitivo pertenece solo a la religión o al cansancio". Es decir, la obra es tal en tanto es releída, traducida, reversionada y reinterpretada.

PL: Siguiendo con esta idea de traducción, ¿considerás que existe una evolución de la interpretación musical?

LG: La hay, pero es circular y ascendente, como diría Kandinsky. El intérprete del S. XIX no tiene la misma mirada que el intérprete del S. XXI y el oyente tampoco. Entonces, la obra musical se transfiere en su origen a través de una pauta muy imprecisa llamada partitura y a partir de ahí evoluciona y se va transformando. No tiene sentido, al menos para mí, desvelarse intentando lograr una supuesta fidelidad a los deseos del compositor. El propio compositor puede tener una mirada distinta cuando se para como intérprete de sus propias obras. Hay muchos ejemplos clarísimos de esto, pero uno de los más fascinantes es la grabación de Gustav Mahler tocando al piano las reducciones de sus propias sinfonías. En casi todos los pasajes hace lo que en su propia partitura pide que no se haga. Entonces, eso significa que la mirada de Mahler como intérprete aun frente a sus propias obras es diferente que su propia mirada como compositor.

PL: ¿Cómo pensás que se origina la supuesta fidelidad que la tradición clásica interpretativa tiene hacia el texto musical o incluso al compositor?

LG: Pienso que es una limitación generada en el pánico que a muchos músicos les genera la espontaneidad y la creación. Hace más de un siglo, la improvisación era una práctica normal. Luego, eso se perdió y junto con ese alejamiento fue surgiendo una especie de tendencia negativa -siempre de acuerdo a mi mirada, por supuesto- de que el estudio de la música se centra en la "Conservación". De allí, el tan mentado nombre de "Conservatorio", ¿Conservar qué? ¿Una tradición? Me parece bien conocer las formas en que se interpretaron las obras a través del tiempo, pero nuestra función no es conservarlas, sino conocerlas para poder a través de una adecuada y original combinación, crear otras relecturas. De eso se trata. Entonces, ese culto al texto, sumado a la falta de una adecuada instrucción musical que nos enseñe a entender lo que la música nos dice a través del lenguaje que le es propio, produce en muchos casos un temor pánico al crecimiento interpretativo. Vuelvo a citar a Arnold Schoenberg, cuando dice:

Son relativamente pocas las personas capaces de comprender, en términos puramente musicales, lo que la música expresa. Suponer que una pieza de música debe acumular imágenes de una u otra especie y que si estas faltan la pieza no ha sido entendida o carece de valor, es algo tan extendido como solamente puede serlo lo falso y lo vulgar ${ }^{5}$

PL: Esta supuesta fidelidad hacia la partitura, ¿tendrá que ver con la concepción de la música como "obra" o "producto" más que como "hecho" o "proceso"?

LG: Insisto con lo mismo: la obra no es un producto, sino un proceso. La obra existe en tanto crece, solo crece si es releída. Hay millones de ejemplos al respecto. Tomemos, por ejemplo, una grabación de los Conciertos Brandenburgueses de Bach realizada por un gran intérprete como Leopold Stokowsky en los años “40 del siglo pasado: una orquesta completa de cien integrantes, sonoridades plenas, recursos románticos, etc. A nadie se le ocurriría hoy tocar de esa manera una obra de Bach, pero la partitura es la misma. Es decir: en interpretación también hay modas y ellas le agregan a la obra distintas miradas desde distintos ángulos. No es que hoy se toque necesariamente mejor que hace 70 años, se toca diferente, y está muy bien que así sea.

PL: Hace algunos años llevaste adelante un proyecto que según tus propias palabras es uno de los que más emoción ha traído a tu vida: la reconstrucción e interpretación de la música original del filme Tiempos Modernos de Charles Chaplin. ¿Qué es lo que despertó tanto interés de aquel trabajo?

LG: Creo que Tiempos Modernos es uno de los mejores films de la historia del cine. En ese caso especial, al tratarse de cine mudo, la música cumple un rol importantísimo, siendo la base para las escenas de pantomima, las cuales están montadas con un concepto absolutamente coreográfico. Esta música figura en los créditos como escrita por Chaplin, pero en realidad no es así, ya que fue escrita por David Raksin, importante 
compositor de Hollywood. Quizás Chaplin haya tirado alguna idea ya que era músico aficionado, pero la partitura, claramente, ha sido escrita por un compositor de muchísimo oficio.

PL: En tu programa de Radio Nacional "Tarde transfigurada”, le has dado un espacio interesante a la música de cine. ¿Qué aportes pensás que la música cinematográfica ha brindado a la música autónoma?

LG: La música de cine me apasionó siempre y me gusta frecuentarla todo lo que puedo. En poco más de un siglo de cinematografía se han desarrollado varios estilos, modas y técnicas. Creo que un buen film scoring es esencial para que una buena película funcione. Creo que en general es la música de cine la que ha tomado más de la música autónoma que al revés. Por ejemplo, los grandes compositores de Hollywood como MIklos Rosza, Erich Korngold, Bernard Hermann y más recientemente John Williams, tomaron sin pudor materiales de Respighi, Wagner, Bartok, Richard Strauss y Strawinsky. En la ex-URSS se dio el extraño caso de una dupla genial formada por el director Sergei Eisenstein y el compositor Sergei Prokofiev, quienes colaboraron en muchas películas icónicas de los años “30 y “40. En algunos casos, como la famosa escena de la batalla sobre el hielo perteneciente al film Alexander Nevsky, la música funcionó como base para la estructura fílmica, pero eso es poco común. Aquí en Argentina también hubo una importante tradición de música para cine. Compositores como Alberto Ginastera, Virtú Maragno, Gilardo Gilardi y otros escribieron excelente música para diferentes películas rodadas en nuestro país.

\section{Notas}

1 Entre otras, dirigió la Filarmónica de Israel, la Sinfónica de Jerusalem y la Sinfonietta Beer Sheva.

2 Teatro Municipal de Sao Paulo, Teatro Nacional Serbio, Teatro Municipal de Santiago de Chile, SODRE (Uruguay), Opera Nacional de Eslovenia, Teatro Argentino de La Plata.

3 Se destacó en presentaciones al frente de la Sinfónica Nacional de Islandia, Orquesta OFUNAM, Sinfónica del Estado de México, Orquesta de Bellas Artes (MX), Orquesta del Teatro Nacional Claudio Santoro de Brasilia, Orquesta de la Radio y Televisión de Serbia, Sinfónica Nacional de Macedonia, Slovenian Philharmonic, Filarmónica de Bogotá, Sinfónica Nacional de Colombia, Sinfónica Nacional de Chile, Sinfónica Nacional de Cuba, Sinfónica de Venezuela, OSUSP (Sao Paulo), Dohnanyi-Budapest Orchestra, etc

4 La Boheme, La traviata, Tosca, Mme Butterfly, Le nozze di Figaro, La Clemenza di Tito, Rigoletto, Carmen y Cosifan tutte.

5 Schoenberg, Arnold (1963). Capítulo 1: "La afinidad con el texto", en El estilo y la idea. Ed. Ser y Tiempo Madrid. 